\title{
Preface to the 1996 Edition
}

The reprint of Textile Traditions of Mesoamerica and the Andes: An Anthology makes available to a larger audience a wide-ranging volume that explores theory and concept, cultural meaning and material culture, as well as specific traditions. The audience includes scholars and students in disciplines such as Latin American studies, art and textile histories, material culture, anthropology, women's studies, and the interested general public. Some articles include uncharted regions on the textile map; others offer information that has not been recorded elsewhere.

Updated biographies of contributors illustrate how scholars have developed ideas presented in this volume over the past decade. A list of additional references covers recent publications in relevant areas. There remains a need for more textile studies in all areas covered by this volume, including:

- in-depth fieldwork-based studies like Ackerman's work in Abancay, Peru, and Hendrickson's study in Tecpán, Guatemala;

- ethnohistoric and iconographic studies such as Wilson's essay on colonial and historic textiles in Cuzco, Peru, and McCafferty and McCafferty's essay on late pre-Hispanic Central Mexican textile ideologies;

- and broadly synthetic and interpretive studies like Berlo's contribution, "Beyond Bricolage."

The studies published here fill a gap in the textile literature. Yet they also point out how many more research questions there are to explore. 
xvi Preface

These include the role of indigenous textiles in the world market, transnational and global exchanges through cooperatives and alternate trading organizations, local impact of market expansion, dress and gender, and dress and ethnicity.

Grateful thanks from all contributors for this new edition are due to Theresa May, Assistant Director and Executive Editor of the University of Texas Press.

\author{
Margot Blum Schevill, \\ Janet Catherine Berlo, \\ Edward B. Dwyer \\ January 10, 1996
}

